\title{
An Unusual Case of Neurogenic Sexual Dysfunction Due to Lead Exposure
}

\author{
S. Ali Khan ${ }^{2}$, Terry Whyard ${ }^{2}$, Sowmya Muthiki ${ }^{1}$, Musharaf Khan ${ }^{2}$, Supriya Mishra ${ }^{1}$, Emily Hughes ${ }^{1}$, \\ Aleef Rahman ${ }^{1}$, Vidit Sharma ${ }^{1}$ and Srinivas Pentyala*,1,2 \\ ${ }^{I}$ Departments of Anesthesiology and ${ }^{2}$ Urology, Stony Brook University Medical Center, Stony Brook, NY, USA
}

\begin{abstract}
An unusual case of sexual dysfunction due to autonomic neuropathy, secondary to lead poisoning is reported in a radiator repair car mechanic. Pathophysiology of sexual dysfunction secondary to lead induced autonomic neuropathy is discussed. Neurologists who treat sexual dysfunction should be made aware of relationship of metal toxicity producing neurogenic sexual dysfunction.
\end{abstract}

Keywords: Lead poisoning, erectile dysfunction, PDE-5 inhibitors.

\section{INTRODUCTION}

More than 30 million men suffer from erectile dysfunction in US and 150 million worldwide [1]. Erectile dysfunction is frequently a serious symptom or a surrogate marker of an underlying disease [2]. There is no perfect neurogenic erectile dysfunction, only an imperfect or delayed diagnosis of a serious underlying neurologic disease. Men who suffer from erectile dysfunction should be investigated for an underlying suspected disease state. We present a rare case of erectile dysfunction secondary to neurogenic sexual dysfunction because of lead poisoning [3-6].

\section{CASE REPORT}

A 44 year old male radiator repair car mechanic from India was presented at Stony brook University Hospital in Stony Brook, NY complaining of fatigue, dizzy spells, failure to focus, habitually dropping repairing tools, numbness of penis, constipation, periodic headaches, depression, intermittent episodes of abdominal pain and urinary hesitancy. His sexual symptoms included, poor libido, unable to get or maintain an erection, decreased ejaculate and altered orgasms for 3 years duration. He was treated with aphrodisiacs powder in his native country (India) and his sexual symptoms worsened. He had failed all Phosphodiesterase-5 (PDE-5) inhibitors and self injection with prostaglandins for erectile dysfunction.

\section{Physical Examination}

The patient was alert, ambulatory, with a blood pressure of 140/90, and ENT examination was normal. Oral cavity examination revealed normal teeth, and tongue and tonsillar fossa was found to be normal. Gingiva revealed a narrow leaden-blue line, about a few $\mathrm{mm}$ in width. Heart and lungs were normal to palpation and auscultation. Abdomen was

*Address correspondence to this author at the Department of Anesthesiology, Stony Brook Medical Center, Stony Brook, NY, USA;

Tel: 631-444-2974; Fax: 631-444-2907;

E-mail: srinivas.pentyala@stonybrook.edu soft with active bowel sounds and no bruits. Spine, perineum, and external genitalia were also found to be normal. Rectal examination revealed lax sphincter tone and prostate gland evaluation revealed no nodules or masses. Peripheral pulses were normal and there was no motor or sensory deficit. There was a decreased sensation in the perineal triangle.

\section{Lab Tests}

Complete blood count was normal and a peripheral blood smear basophilic stippling and anemia work up was negative. Basic metabolic panel tests and liver function tests were also found to be normal. The patient's ante meridiem (AM) total testosterone level was low which is $180 \mathrm{ng} / \mathrm{dL}$ compared to normal range of $250-1100 \mathrm{ng} / \mathrm{dL}$ ), and prolactin and sex hormone binding globulin levels were normal. Hematological work up was performed in view of the patient's occupational background testing for various heavy metals including lead with a suspicion of possible inhalation of car radiator fumes. Blood level of lead was $80 \mathrm{mcg} / \mathrm{dL}$ (normal levels of lead should be less than $20 \mathrm{mcg} / \mathrm{dL}$ ). The patient was suspected to suffer from autonomic neuropathy induced sexual dysfunction secondary to lead poisoning. Patient was uncooperative, refused duplex Doppler of penis, nerve conduction, and neurobehavioral cognitive function studies, to confirm lead poisoning. He was strongly advised to stop working with car radiators immediately and was clued-up of the occupational hazard of lead poisoning. The patient was given Dimercaprol (British AntiLewisite) parenterally $(4 \mathrm{mg} / \mathrm{kg}$ body $\mathrm{wt})$ daily as a lead chelator. The patient's lead levels decreased to $7 \mathrm{mcg} / \mathrm{dL}$ in 7 days. His sexual symptoms and anemia improved, and his AM total testosterone was normal over period of 3 months (tested every 2 weeks) and he started to respond to PDE-5 inhibitors. Further lead levels could not be obtained as the patient was lost to follow up.

\section{DISCUSSION}

Five physiologic phases of normal male sexual cycle consists of libido, penile erection, emission and ejaculation [7], orgasm [8], and detumescence of penis [9]. Male sexual function integrates several pathways which include, 
cerebrospinal, psychogenic, endocrine, vascular, autonomic, somatic and smooth muscle, skeletal muscle and rigid tunica albuginea and envelopes of dual corpora cavernosa. The central and peripheral neurologic pathways involved in sexual function include brain centers, spinal cord, cavernous nerves and pudendal nerve [10]. Anatomy of the cavernous nerves are mixed autonomic nerves that is responsible for penile erection, ejaculation and detumescence [11]. The pudendal nerve plays an essential role in pudendal evoked potentials, last phases of penile erection, threshold of somatosensory reflexes and ejaculation [12]. Decreased libido is secondary to altered hypothalamic-pituitary axis and altered orgasm [13]. Sexual symptoms in the case reported here included poor libido, unable to get a penile erection, ejaculatory and orgasmic dysfunction due to pelvic autonomic neuropathy secondary to lead poisoning $[14,15]$.

Unusual sexual symptoms secondary to neurogenic pathways should draw physician's awareness to the possibility of lead poisoning, particularly in workers with occupational exposure to lead and in areas where lead poisoning is endemic [16]. Lead is present in water [17], paint [18], brass plumbing fixtures [19], ayurvedic medicine [20, 21], aphrodisiacs [22], alternative medications [23], etc. Lead is toxic to numerous organ systems, which include bone marrow, muscles, kidneys, endocrine glands, joints, and nervous system [24-27]. Low-level blood lead levels may be causative factors in cognitive dysfunction, neurobehavioral disorders, neurological damage, hypertension, cardiac dysfunction and renal impairment [28]. Occupational exposure to inorganic lead is main features of this unusual case. Lead poisoning in adults primarily results from exposure by inhalation in the workplace [29]. We suspect that this patient suffered from lead poisoning from inhalation of fumes from car radiators and developed autonomic neuropathies which resulted in erectile dysfunction. Chelator therapy is highly effective in such conditions to restore sexual functionality in patients exposed to heavy metals like lead.

\section{REFERENCES}

[1] Shindel AW. 2009 update on phosphodiesterase type 5 inhibitor therapy part 2: updates on optimal utilization for sexual concerns and rare toxicities in this class. J Sex Med 2009; 6: 2352-64.

[2] Foresta C, Caretta N, Corona G, et al. Clinical and metabolic evaluation of subjects with erectile dysfunction: a review with a proposal flowchart. Int J Androl 2009; 32: 198-211.

[3] Abdul-Rahman A, Ismail S, Hamid R, Shah J. A 20-year follow-up of the mesh wallstent in the treatment of detrusor external sphincter dyssynergia in patients with spinal cord injury. BJU Int 2011; 106: 1510-13.

[4] Khorrami MH, Javid A, Moshtaghi D, Nourimahdavi K, Mortazavi A, Zia HR. Sildenafil efficacy in erectile dysfunction secondary to spinal cord injury depends on the level of cord injuries. Int $\mathrm{J}$ Androl 2011; 33: 861-4.

[5] Kim SH. Post-traumatic erectile dysfunction: doppler US findings. Abdom Imaging 2006; 3: 598-609.

[6] Dey J, Shepherd MD. Evaluation and treatment of erectile dysfunction in men with diabetes mellitus. Mayo Clin Proc 2002; 77: $276-82$.
[7] Motofei IG, Rowland DL. Neurophysiology of the ejaculatory process: developing perspectives. BJU Int 2005; 96: 1333-8.

[8] Richters J. Bodies, pleasure and displeasure. Cult Health Sex 2009; 11: 225-236.

[9] Ponseti J, Kropp P, Bosinski HA. Brain potentials related to the human penile erection. Int J Impot Res 2009; 21: 292-300.

[10] DeFalco T, Capel B. Gonad morphogenesis in vertebrates: divergent means to a convergent end. Annu Rev Cell Dev Biol 2009; 25: 457-82.

[11] Lehrfeld T, Lee DI. The role of vacuum erection devices in penile rehabilitation after radical prostatectomy. Int J Impot Res 2009; 21 : 158-64.

[12] Rubino C, Figus A, Dessy LA, et al. Innervated island pedicled anterolateral thigh flap for neo-phallic reconstruction in female-tomale transsexuals. J Plast Reconstr Aesthet Surg 2009; 62: 45-49.

[13] Pfaus JG. Pathways of sexual desire. J Sex Med 2009; 6: 1506-33.

[14] Anis TH, ElKaraksy A, Mostafa T, et al., Chronic lead exposure may be associated with erectile dysfunction. J Sex Med 2007; 4: 1428-36.

[15] Madan K, Sharma PK, Makharia G, Poojary G, Deepak KK. Autonomic dysfunction due to lead poisoning. Auton Neurosci 2007; 132: 103-6.

[16] Cunningham M. Chronic occupational lead exposure: the potential effect on sexual function and reproductive ability in male workers. AAOHN J 1986; 34: 277-9.

[17] Malik N, Biswas AK, Qureshi TA, Borana K, Virha R. Bioaccumulation of heavy metals in fish tissues of a freshwater lake of Bhopal. Environ Monit Assess 2010; 160: 267-76.

[18] Huang SL, Yin CY, Yap SY. Particle size and metals concentrations of dust from a paint manufacturing plant. J Hazard Mater 2010; 174 839-42.

[19] Tam YS, Elefsiniotis P. Corrosion control in water supply systems: effect of $\mathrm{pH}$, alkalinity, and orthophosphate on lead and copper leaching from brass plumbing. J Environ Sci Health A Tox Hazard Subst Environ Eng 2009; 44: 1251-60.

[20] Saper RB, Phillips RS, Sehgal A, et al. Lead, mercury, and arsenic in US- and Indian-manufactured Ayurvedic medicines sold via the Internet. JAMA 2008; 300: 915-23.

[21] Dunbabin DW, Tallis GA. Popplewell PY, Lee RA. Lead poisoning from Indian herbal medicine (Ayurveda). Med J Aust 1992; 157: 835-6.

[22] Dolan G, Jones AP, Blumsohn A, Reilly JT, Brown MJ. Lead poisoning due to Asian ethnic treatment for impotence. J R Soc Med 84; 1991: 630-1.

[23] Shamshirsaz AA, Yankowitz J, Rijhsinghani A, Greiner A, Holstein SA, Niebyl JR. Severe lead poisoning caused by use of health supplements presenting as acute abdominal pain during pregnancy. Obstet Gynecol 2009; 114: 48-50.

[24] Wild P, Bourgkard E, Paris C. Lung cancer and exposure to metals: the epidemiological evidence. Methods Mol Biol 2009; 472: 13967.

[25] Murata K, Iwata T, Dakeishi M, Karita K, Lead toxicity: does the critical level of lead resulting in adverse effects differ between adults and children? J Occup Health 2009; 51: 1-12.

[26] Mishra KP. Lead exposure and its impact on immune system: a review. Toxicol In vitro 2009; 23: 69-72.

[27] Johnson FO. Atchison WD. The role of environmental mercury, lead and pesticide exposure in development of amyotrophic lateral sclerosis. Neurotoxicology 2009; 30: 761-5.

[28] Earle CM, Stuckey BG. Biochemical screening in the assessment of erectile dysfunction: what tests decide future therapy? Urology 2003; 62: 727-31.

[29] Virji MA, Woskie SR. Pepper LD. Skin and surface lead contamination, hygiene programs, and work practices of bridge surface preparation and painting contractors. J Occup Environ Hyg 2009; 6: 131-42. 